\title{
Assessment of total body water in paediatric patients on dialysis
}

\author{
E. Wühl ${ }^{1}$, Ch. Fusch ${ }^{2}$, K. Schärer ${ }^{1}$, O. Mehls ${ }^{1}$ and F. Schaefer ${ }^{1}$ \\ ${ }^{1}$ Division of Pediatric Nephrology, University Children's Hospital, Heidelberg, Germany; and ${ }^{2}$ Department of Neonatology, \\ University Women's Hospital, Bern, Switzerland
}

\begin{abstract}
Background. Various anthropometric techniques are used to assess total body water in children on dialysis; however, their predictive accuracy and precision has not been validated.

Methods. We compared total body water measurements obtained by deuterium oxide $\left(\mathrm{D}_{2} \mathrm{O}\right)$ dilution with predictions of total body water from (1) height and weight, (2) skinfold measurements, and (3) bioelectrical impedance analysis, using previously published formulae for healthy children. Measurements were performed in 14 patients on peritoneal and in nine patients on haemodialysis, aged 4-22 years.

Results. In the total population of dialysed patients, weight was the strongest single predictor of total body water $\left(R^{2}=0.93\right)$, followed by the resistance index $\left(\mathrm{RI}=\right.$ height $^{2} /$ impedance; $\left.\mathrm{R}^{2}=0.85\right)$ and height $\left(\mathrm{R}^{2}=\right.$ 0.93 ). A prediction formula based on height and weight predicted total body water with a residual mean square error (RMSE) of 1.971 (coefficient of variation (CV) = $10.0 \%$ ) and with a systematic overestimation of true total body water by $0.4 \%$. A prediction equation based on skinfold measurements yielded a total body water estimate with an RMSE of $2.151(\mathrm{CV}=10.5 \%)$ and overpredicted true total body water by an average of $2.2 \%$. Using three published prediction equations incorporating RI, RMSEs of $2.781(\mathrm{CV}=14.1 \%)$ with a mean under- or overestimation of true total body water by $6.9,7.1$, and $0.8 \%$ respectively, were achieved. The prediction of total body water was optimized by linear combinations of RI or the log-transformed sum of four skinfolds (logsum) with weight by the following equations:
\end{abstract}

$$
\begin{aligned}
\text { total body water }(1)= & 9.97-3.13 \times \text { logsum } \\
& +0.59 \times \text { weight }(\mathrm{kg}) \\
\left(\mathrm{R}^{2}=0.951 ; \mathrm{RMSE}=\right. & 1.67 \mathrm{l} ; \mathrm{CV}=8.17 \%) . \\
\text { total body water }(1)= & 1.99+0.144 \\
& \times \mathrm{RI}\left(\mathrm{Ohm} / \mathrm{cm}^{2}\right) \\
& +0.40 \times \text { weight }(\mathrm{kg}) \\
\left(\mathrm{R}^{2}=0.949 ; \mathrm{RMSE}=\right. & 1.67 \mathrm{l} ; \mathrm{CV}=8.53 \%) .
\end{aligned}
$$

Correspondence and offprint requests to: Dr F. Schaefer, UniversitătsKinderklinik, Im Neuenheimer Feld 150, D-69120 Heidelberg, Germany.
The fit of these prediction formulae, which were derived from the total population, did not differ significantly between haemo- and peritoneal dialysis patients or between boys and girls.

Conclusions. Both skinfold measurements and bioelectrical impedance analysis can be used to improve the height- and weight- based prediction of total body water in children on dialysis

Key words: bioelectrical impedance analysis; deuterium oxide; skinfold measurements; children; dialysis; body composition

\section{Introduction}

Although the assessment of the state of hydration is essential in the care of dialysed children, clinicians usually rely on crude signs such as skin turgor, blood pressure, or major changes in body weight. Reliable methods to determine total body water, such as isotope dilution, densitometry, or the recently developed total body electrical conductivity and dual photon absorptiometry are not available on a routine basis, are invasive, or are difficult to apply in young children. Equations to estimate total body water from combinations of simple, non-invasive anthropometric measurements such as height, weight, or skinfold thicknesses have been developed and validated in healthy children, but their reliability in children on dialysis, who are usually stunted and have a great variability of body water contents, has not been validated.

Recently, whole-body bioelectrical impedance analysis has been introduced as a precise, quick and noninvasive method to assess total body water [1-3]. Being applicable even in small children, this technique appears particularly suitable for everyday clinical use in paediatric dialysis patients. However, recent studies have shown that the relationship between bioelectrical impedance analysis and total body water may differ between adults and children [4], and may depend on the average state of hydration of a population. Furthermore, it has not been studied whether total body water can be predicted more precisely with bioelectrical impedance analysis than with conventional 
anthropometric techniques in patients on dialysis. No experience exists with the application of bioelectrical impedance analysis in patients on continuous peritoneal dialysis. Therefore we have evaluated the predictive power of bioelectrical impedance analysis in comparison with conventional anthropometric techniques in cohorts of children on haemo- and peritoneal dialysis, using deuterium oxide $\left(\mathrm{D}_{2} \mathrm{O}\right)$ dilution as the reference techniques to measure total body water.

\section{Subjects and methods}

\section{Patients}

Twenty-three paediatric patients in the chronic dialysis programme at Heidelberg University Children's Hospital took part in this study. Fourteen patients were on peritoneal, and nine patients on haemodialysis. (Basic characteristics of the children are given in Table 1.) The parents of each child and the adult patients themselves gave written informed consent after thorough information about the study's purposes and procedures.

\section{$\mathrm{D}_{2} \mathrm{O}$ dilution technique}

Total body water was measured using the reference technique of deuterium oxide dilution. One gram $\mathrm{D}_{2} \mathrm{O}$ (purity $99.8 \%$; Merck, Darmstadt, Germany) per kilogram of body weight was administered orally immediately after bag exchange in peritoneal dialysis patients and after the end of a dialysis session in haemodialysis patients respectively. Patients were not allowed to eat or drink from $1 \mathrm{~h}$ prior to until the end of the study. In the haemodialysis patients blood sampling was performed after 1,2 and $3 \mathrm{~h}$. In the peritoneal dialysis patients $2 \mathrm{ml}$ of blood and dialysate were sampled after 2, 3 and $4 \mathrm{~h}$. Serum was frozen at $-20^{\circ} \mathrm{C}$ until analysis. Deuterium enrichment was measured using Fouriertransformed infrared spectroscopy and vacuum distillation as previously described [5-7]. The coefficient of variation (CV) of the method is $<0.5 \% .{ }^{2} \mathrm{H}$ enrichments were corrected by a factor of 1.04 for isotope sequestration.

\section{Bioelectrical impedance analysis}

Bioelectrical impedance analysis was performed with a tetrapolar Body Composition Analyser (BCA, Holtain Ltd. Crymych, Dyfed, UK) using a $50 \mathrm{kHz}, 800 \mu \mathrm{A}$ alternating current and Red Dot ${ }^{\Theta}$ ECG electrodes (3M, VP 2330). The measurements were standardized according to the procedural guidelines of Lukaski et al. [8]. In order to avoid any measurement bias from variable positioning of the electrodes, the electrodes were placed at defined positions on the right wrist and ankle, and care was taken that the distance between the electrodes was $3 \mathrm{~cm}$. The patients were measured in the supine position, with arms and legs spread at an angle of $30^{\circ}$. With this standardization, we have previously reported intra- and interobserver $\mathrm{CVs}$ of measurement of 0.5 and $1.5 \%$ respectively [9]. The mean of three sequential readings was used as measurement value. Since bioelectrical impedance, i.e. the resistance to an alternating electrical current in the body reflects tissue water contents, whole-body impedance reflects total body water. The volume of a conducting body is proportional to the square of the length of the body. Therefore, total body water is usually expressed by a linear equation incorporating the Resistance Index, (RI), i.e. height ${ }^{2} /$ impedance [10].

\section{Anthropometry}

All anthropometric measurements were performed according to standard techniques. Standing height was measured to the nearest $0.1 \mathrm{~cm}$ with a Holtain wall stadiometer (Holtain Ltd., Crosswell, Crymych, Dyfed, UK). Weight was determined on a digital scale (SECA, Hamburg, Germany) with a precision of $0.1 \mathrm{~kg}$. Skinfold thicknesses were determined to the nearest $0.2 \mathrm{~mm}$ at the left biceps, triceps, subscapular, and suprailiac sites with a Holtain skinfold caliper calibrated to exert a constant pressure of $10 \mathrm{~g} / \mathrm{mm}^{2}$ (Holtain Ltd.) The log-transformed sum of biceps, triceps, subscapular, and suprailiacal skinfolds (logsum) was used as a parameter in the statistical analysis. Anthropometry was performed together with the bioelectrical impedance measurement at the end of the study, i.e. in haemodialysis patients $3 \mathrm{~h}$ after the end of a dialysis session, in peritoneal dialysis patients at the end of a 4-h dialysate dwell.

Estimates of total body water were derived from height and weight according to the equations of Cheek et al. [11], and from weight and the sum of triceps and subscapular skinfolds according to Slaughter et al. [12]

\section{Statistical analysis}

The SAS package was used for statistical analysis [13]. Possible associations between total body water measurements by $\mathrm{D}_{2} \mathrm{O}$ dilution and various anthropometric measurements or age were evaluated using linear and non-linear regression analysis. Stepwise multiple regression analysis was used to evaluate the precision and accuracy of parameter combinations in predicting total body water measurements by $D_{2} \mathrm{O}$ dilution. The applicability of the best-fitting equation developed by this procedure for the two genders and the two dialysis modalities was checked by evaluating the significance of the mean difference between the measured and estimated total body water from zero by use of Wilcoxon's signedranks statistic in each subgroup separately.

Table 1. Patient characteristics (median (range))

\begin{tabular}{|c|c|c|c|c|c|}
\hline Treatment modality & $n$ & Sex & $\begin{array}{l}\text { Age } \\
\text { (years) }\end{array}$ & $\begin{array}{l}\text { Height } \\
\text { (cm) }\end{array}$ & $\begin{array}{l}\text { Weight } \\
(\mathrm{kg})\end{array}$ \\
\hline Peritoneal dialysis & 14 & & $\begin{array}{l}11.9 \\
(4.1-20.3)\end{array}$ & $\begin{array}{l}123.9 \\
(91.0-163.0)\end{array}$ & $\begin{array}{l}25.9 \\
(9.0-57.9)\end{array}$ \\
\hline Haemodialysis & 9 & $4 \mathrm{~m} / 5 \mathrm{f}$ & $\begin{array}{l}16.6 \\
(9.6-22.6)\end{array}$ & $\begin{array}{l}147.1 \\
(130.0-158.8)\end{array}$ & $\begin{array}{l}36.3 \\
(26.9-49.1)\end{array}$ \\
\hline
\end{tabular}




\section{Results}

\section{$\mathrm{D}_{2} \mathrm{O}$ equilibration in dialysed patients}

Both plasma and dialysate $\mathrm{D}_{2} \mathrm{O}$ concentrations had reached steady state and complete equilibration within the body $4 \mathrm{~h}$ after ingestion as indicated by statistically non-significant differences between (1) the 2-, 3- and 4-h plasma values, and (2) between the 4-h plasma

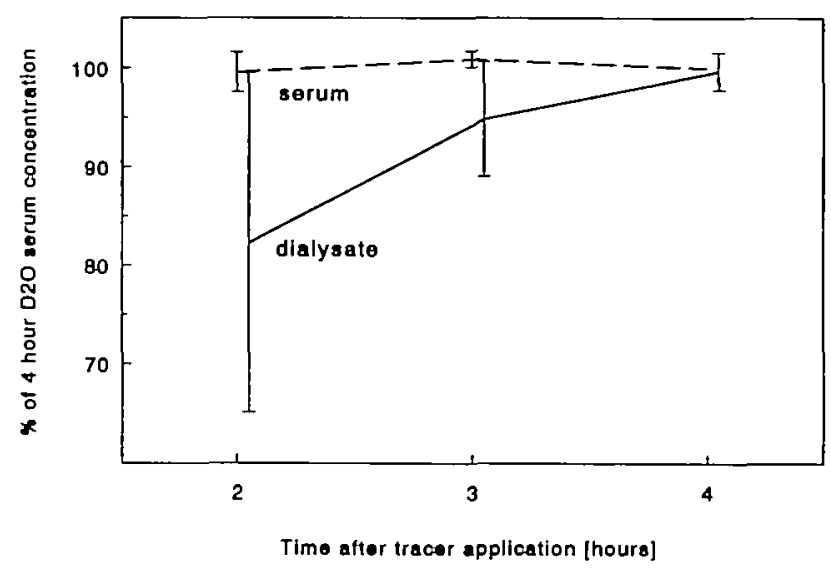

Fig. 1. Equilibration of $\mathrm{D}_{2} \mathrm{O}$ in serum (--) and dialysate (-) in peritoneal dialysis patients 2,3 and $4 \mathrm{~h}$ after tracer application (mean $\pm \mathrm{SD}$ ).

Table 2. Regression analysis of the relationship between total body water measurement by $\mathrm{D}_{2} \mathrm{O}$ dilution and various single or combined anthropometnc variables

\begin{tabular}{lllc}
\hline Variables & $\mathbf{R}^{2}$ & RMSE (1) & CV (\%) \\
\hline Weight & 0.93 & 1.87 & 9.12 \\
RI & 0.85 & 2.84 & 13.9 \\
Height & 0.79 & 3.34 & 16.3 \\
logsum & 0.34 & 5.98 & 29.2 \\
Weight, logsum & 0.951 & 1.67 & 8.53 \\
Weight, RI & 0.949 & 1.67 & 8.53 \\
Weight, Height & 0.94 & 1.88 & 9.19 \\
RI, logsum & 0.87 & 2.63 & 12.8 \\
\hline
\end{tabular}

and dialysate levels in the peritoneal dialysis group (Figure 1). The plasma $\mathrm{D}_{2} \mathrm{O}$ concentration $3 \mathrm{~h}$ after administration was used as the steady-state value in the subsequent calculations. In the peritoneal dialysis population, the dialysate volume was subtracted from the calculated total body water to achieve true total body water. In concordance with previous studies [14], we observed no significant influence of dialysate fluid volume on RI in the peritoneal dialysis patients.

\section{Prediction of total body water measurement by $\mathrm{D}_{2} \mathrm{O}$} dilution $\left(T B W_{D_{2} O}\right.$ ) by height and weight

As shown in Table 2 weight was the most closely correlated single parameter correlated with $\mathrm{D}_{2} \mathrm{O}$. The linear combination of weight and height predicted $\mathrm{TBW}_{\mathrm{D}_{2} \mathrm{O}}$ with a $\mathrm{CV}$ of $9.2 \%$. The height and weight based equations (Cheek et al. [11]) predicted $\mathrm{TBW}_{\mathrm{D}_{2} \mathrm{O}}$ for our patients without a systematic error (difference $0.13 \pm 1.951$ ) and with a $\mathrm{CV}$ of prediction of $10.0 \%$ (Table 3 ).

\section{Prediction of $T B W_{D_{2} O}$ by bioelectrical impedance}

The optimal non-linear combination of resistance and height was given by exponents of -1 for impedance and +2 for height; replacement of height by weight or a combination of these did not further reduce the residual variance in the model. Therefore the term height ${ }^{2} /$ impedance (resistance index; RI) was used in the further calculations. RI was closely correlated with $\mathrm{TBW}_{\mathrm{D}_{2} \mathrm{O}}\left(\mathrm{R}^{2}=0.85\right.$, see Table 2, Figure 2). Possible associations between $T B W_{\mathrm{D}_{2} \mathrm{O}}$ and various anthropometric measures and age were evaluated by linear regression analysis (Table 2 ). The predictive power of RI was not superior to that of weight alone. The variance in the prediction of $\mathrm{TBW}_{\mathrm{D}_{2} \mathrm{O}}$ was reduced by $60 \%$ by combining RI and weight as independent variables. Inclusion of further variables did not further reduce the residual variance of $T B W_{D_{2}} \mathrm{O}$. The equation of best fit reads as follows:

$$
\begin{aligned}
& \text { Total body water } \quad(1)=1.99+0.144 \\
& \times \operatorname{RI}\left(\mathrm{cm}^{2} / \mathrm{Ohm}\right)+0.40 \times \text { weight }(\mathrm{kg}) .
\end{aligned}
$$

Table 3. Predictive accuracy and precision of total body water estimates obtained by bioelectrical impedance analysis, skinfold equations,

\begin{tabular}{|c|c|c|c|c|c|c|}
\hline Authors & Study population & Parameters & $\begin{array}{l}\text { Difference } \\
\text { measured- } \\
\text { estimated (1) }\end{array}$ & $\mathrm{R}^{2}$ & RMSE (1) & $\begin{array}{l}\text { CV } \\
(\%)\end{array}$ \\
\hline Danford et al [17] & Healthy prepubertal children & RI & $-1.45 \pm 3.12^{*}$ & 0.846 & 2.78 & 14.1 \\
\hline Davies et al. $[15]$ & $\begin{array}{l}\text { Healthy young adults (mean } \\
\text { age } 18.3 \text { years) }\end{array}$ & RI & $1.32 \pm 2.86^{*}$ & 0.846 & 2.78 & 14.1 \\
\hline Gregory et al. [16] & Children with growth disorders & RI & $1.60 \pm 2.73^{* *}$ & 0.846 & 2.78 & 14.1 \\
\hline Choek et al. $[11]$ & Healthy children & Height, weight & $0.13 \pm 1.95$ & 0.922 & 1.97 & 10.0 \\
\hline Slaughter et al. [12] & $\begin{array}{l}\text { Healthy children and } \\
\text { adolescents }\end{array}$ & $\begin{array}{l}\text { Skinfolds, pubertal } \\
\text { stage, sex }\end{array}$ & $-0.27 \pm 2.13$ & 0.914 & 2.15 & 10.5 \\
\hline This study & Paediatric dialysis patients & $\begin{array}{l}\text { (1) weight, skinfolds } \\
\text { (2) weight, RI }\end{array}$ & $\begin{array}{l}0.17 \pm 1.60 \\
0.26 \pm 1.55\end{array}$ & $\begin{array}{l}0.951 \\
0.949\end{array}$ & $\begin{array}{l}1.67 \\
1.67\end{array}$ & $\begin{array}{l}8.53 \\
8.53\end{array}$ \\
\hline
\end{tabular}
and measurements of height and weight

$* P<0.05$

$* * P<0.01$. 


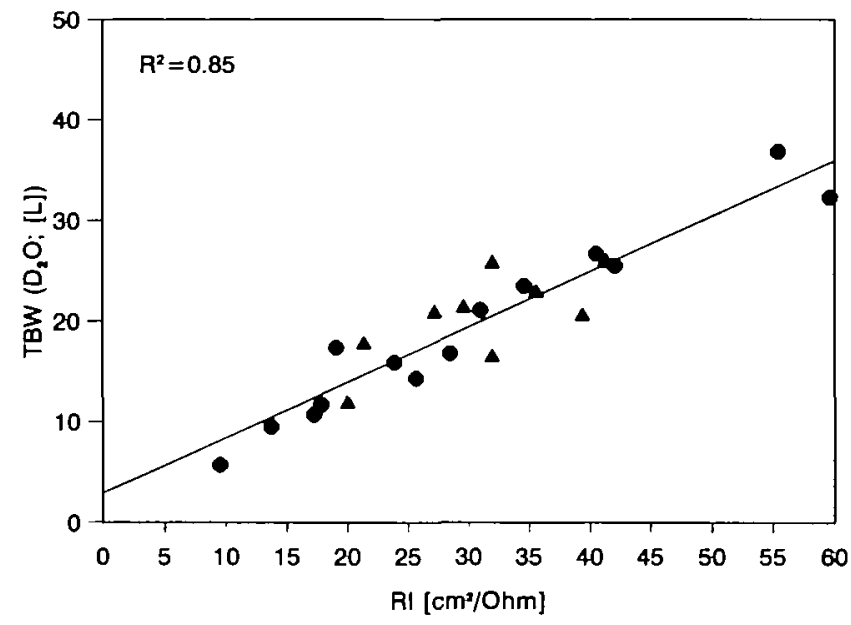

Fig. 2. Association between $T B W_{D_{2} O}$ and RI ( $\Delta$ haemodialysis patients, - peritoneal dialysis pattents). Best fitting regression equation: $\mathrm{TBW}_{\mathrm{D}_{2} \mathrm{O}}=2.82+0.55 \times \mathrm{RI}$.

Using this equation, $\mathrm{TBW}_{\mathrm{D}, \mathrm{O}}$ was predicted with an $\mathrm{R}^{2}$ of 0.949 (Figure 3a). (3) The RMSE was $1.67 \mathrm{l}$, corresponding to a $\mathrm{CV}$ of $8.5 \%$.

The predictive accuracy and precision of the bestfitting equation did not differ between boys (mean $\pm S D$ difference measure-predicted total body water: $0.3 \pm 1.01, \mathrm{R}^{2}=0.92, \mathrm{CV}=3.3 \%$ ) and girls (difference, $0.17 \pm 1.991, \mathrm{R}^{2}=0.93, \mathrm{CV}=9.9 \%$ ). Also, no significant deviation of predicted from measured total body water was observed in patients on haemodialysis (difference: $0.3 \pm 2.01, \mathrm{R}^{2}=0.69, \mathrm{CV}=9.4 \%$ ) and peritoneal dialysis (difference: $0.15 \pm 1.21, \mathrm{R}^{2}=0.98, \mathrm{CV}=$ $6.6 \%$ ) respectively. However, predictive precision was better in peritoneal dialysis ( $\mathrm{RMSE}=1.28 \mathrm{l}$ ) than in haemodialysis patients ( $\mathrm{RMSE}=3.91$ ). Three published bioelectrical impedance derived formulae [15-17] showed a systematic error between -1.45 and +1.601 (CV for all equations 14.1\%) (Table 3 ).

\section{Prediction of $T B W_{D_{2}}$ by skinfold measurements}

Total body water was predicted by weight alone with an $R^{2}$ of 0.93 . This correlation was significantly improved by addition of logsum as a second independent predictor. The best-fitting equation reads as follows:

total body water $(1)=9.97+0.59 \times$ weight $(\mathrm{kg})$

$$
+3.13 \times \text { logsum. }
$$

With this equation, $T B W_{D_{2} O}$ (1) was predicted with an $\mathrm{R}^{2}$ of $0.95 \quad(\mathrm{RMSE}=1.671, \quad \mathrm{CV}=8.53 \%$ ) (Figure $3 \mathrm{~b}$ ). The accuracy and precision of the bestfitting equation did not differ systematically between the genders. In boys, the mean ( \pm SD) difference between measured and predicted total body water was $0.5 \pm 1.31$, the $R^{2}$ was 0.98 , and the CV $4.3 \%$ ); in girls the mean difference was $-0.12 \pm 1.95 \mathrm{l}$, the $\mathrm{R}^{2} 0.93$, and the CV 9.6\%. Also, no significant deviation of predicted from measured total body water was observed in patients on haemodialysis (difference:
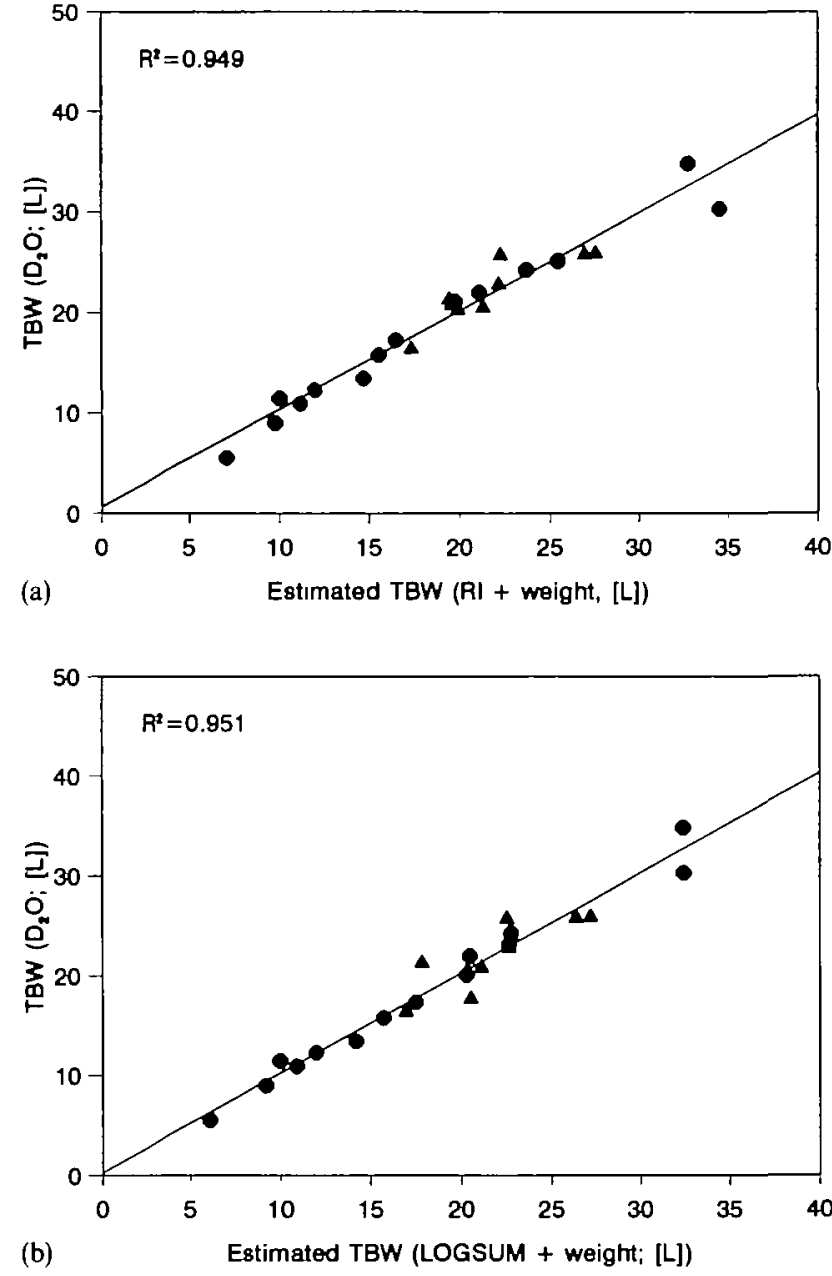

Fig. 3. (a) Relationship between $\mathrm{TBW}_{\mathrm{D}_{2} \mathrm{O}}$ and total body water estimated by RI and welght.

(b) Relationship between $\mathrm{TBW}_{\mathrm{D}, \mathrm{O}}$ and total body water estimated by skinfold thicknesses and weight. $\triangle$ Haemodialysis patients, peritoneal dialysis patients.

$\left.0.25 \pm 1.81, \mathrm{R}^{2}=0.95, \mathrm{CV}=8.5 \%\right)$ and peritoneal dialysis (difference: $0.05 \pm 1.61, \mathrm{R}^{2}=0.97, \mathrm{CV}=8.8 \%$ ) respectively. The formula provided by Slaughter $e t$ al. [12] incorporating skinfold measurements, gender, and pubertal development overpredicted $\mathrm{TBW}_{\mathrm{D}_{2} \mathrm{O}}$ by $0.27 \pm 2.131$ with a CV of prediction of $10.5 \%$ (Table 3).

\section{Discussion}

This study provides the first validation of various anthropometric techniques estimating total body water in paediatric patients with end-stage renal failure. As the experience with isotope dilution in children with end-stage renal failure is limited, the use of the $\mathrm{D}_{2} \mathrm{O}$ technique as a reference technique necessitated validation of this method in the particular settings of haemoand peritoneal dialysis. Patients in end-stage chronic renal failure frequently exhibit fluid overload, and the compartmental distribution of water may be deranged 
(extracellular/intracellular space, water contents of connective tissue). In addition, peritoneal dialysis patients continuously carry approximately $40 \mathrm{ml} / \mathrm{kg}$ body weight of fluid in their peritoneal cavity. The rate of in-vivo equilibration of water isotopes in this 'extracorporeal' fluid volume must be known to allow correction for this space in the calculation of effective total body water. We were able to demonstrate that equilibration of $\mathrm{D}_{2} \mathrm{O}$ is complete after $3 \mathrm{~h}$ in blood in haemodialysis and after $4 \mathrm{~h}$ in blood and dialysate in peritoneal dialysis patients respectively. To calculate effective total body water the effluent dialysate volume may simply be subtracted from the apparent total body water. Moreover, the complete equilibration of $\mathrm{D}_{2} \mathrm{O}$ in dialysate permits use of the dialysate effluent after an oral load to determine total body water without the need of venepuncture, or saliva or urine sampling.

As in healthy paediatric populations $[18,19]$ total body water was linearly related to the ratio of height ${ }^{2}$ and impedance (RI) in our study population. However, the predictive value of the RI was limited, particularly in patients on haemodialysis. Using one single variable, total body water was predicted with greater precision by weight than by RI. The poor correlation in the haemodialysis patients may be related to the fact that measurements were taken shortly after the dialysis sessions, when water and solutes were still redistributing between intra- and extracellular compartments [20]. It is believed that an electrical current of $50 \mathrm{kHz}$ does not freely pass through cell membranes; therefore whole-body impedance may not uniformly reflect intraand extracellular water [21-23]. In healthy children, this effect is of minor importance because intra- and extracellular water are in a steady-state and their ratio is more or less constant. However, in dialysed children who undergo an acute withdrawal of $10-15 \%$ of their total body water and a major intra-extracellular dysequilibrium of osmotically active compounds (e.g. urea) the imbalanced measurement of intra- and extracellular water may become relevant. Indeed, the recently developed technique of bioelectrical impedance analysis performed at multiple current frequencies has shown that major intra- extracellular fluid shifts occur during dialysis [24]. In addition, since the hydration of the lean body mass is age-dependent [25], precision and accuracy of RI may have been biased by the wide range of ages studied. Despite the limited precision of bioelectrical impedance analysis in measuring total body water, we were able to optimize prediction by combining weight and the $\mathrm{RI}$ in a composite prediction equation. Derived from stepwise multiple regression analysis, this best-fitting formula allowed us to predict total body water with a residual error of 1.671 or $8.5 \%$. Still, one should be aware that even using this formula the $95 \%$ confidence interval for an individual measurement is no less than $\pm 17 \%$ of the true body water value.

Equations to predict total body water from bioelectrical impedance analysis have been established in other paediatric populations [15-17]. Our data indicate that these equations poorly predict total body water of children suffering from end-stage chronic renal failure, thereby again confirming the observation that bioelectrical impedance analysis equations are highly population specific. Equations validated in healthy children may not be simply transferred to diseased populations, but rather require cross-validation, and possibly modification, in the particular population of interest.

The usefulness of bioelectrical impedance analysis in estimating total body water should be assessed not only by the absolute precision and accuracy of the prediction equations, but also by comparison with the alternative anthropometric 'bedside' techniques available to date. The simplest approach would be to use a prediction equation incorporating height and weight, as proposed by Cheek et al. [11] for healthy children. Application of the Cheek equations yielded estimates of remarkable accuracy, with a mean difference from the true value of only 0.131 , whereas the precision of prediction was limited-the mean residual error for the total population was as high as $10 \%$ with the Cheek equations or $9.2 \%$ with the best-fitting heightand weight-derived equation obtained in this study. This level of precision is only slightly lower than that of the best-fitting bioelectrical impedance analysis derived formula, suggesting that the additional information inferred by this technique is small.

The use of calipers to assess skinfold thicknesses is regarded as a relatively crude anthropometric technique. The intra- and interobserver variability of skinfold measurements is in the range of 5 and $10 \%$ respectively [26]. Recent experience suggests, however, that using prediction equations based on skinfold sums combined with weight one can estimate the fat-free mass with the same predictive precision as using bioelectrical impedance derived estimations [9]. In the present study we achieved total body water estimates of limited precision when applying published formulae to our group of dialysed children. However, we were able to construct a formula incorporating the logtransformed sum of skinfold measurements at four body sites by which total body water was estimated with the same predictive power as was achieved using bioelectrical impedance analysis.

In summary, the predictive power of various methods estimating total body water was limited when applied in dialysed children. The published prediction equations based on height and weight alone gave accurate though not very precise estimates of total body water. Their precision was significantly improved by the inclusion of skinfold or bioelectrical impedance measurements. However, even the use of these methods did not reduce the average residual error of estimation to less than approximately $8.5 \%$. Published bioelectrical impedance derived prediction equations validated in other paediatric populations did not yield accurate estimates of total body water. The sources for this residual variability, which was greater than that observed in healthy children, may include unpredictable alterations in the total state of hydration as well 
as fluid and solute dysequilibria between intra- and extracellular compartments.

\section{References}

1. Lukaski HC, Bolonchuk WW. Estimation of body fluid volumes using tetrapolar bioelectrical impedance measurement. Aviat Space Environ Med 1988; 59: 1163-1169

2. Lukaski H, Bolonchuk W, Hall C, Siders W. Validation of tetrapolar bioelectrical impedance method to assess human body composition. J Appl Physiol 1986; 60: 1327-1332

3. Jackson AS, Pollock ML, Graves JE, Mahar MT. Reliability and validity of bioelectrical impedance in determining body composition. J Appl Physiol 1988; 64: 529-534

4. Deurenberg P, Kusters CSL, Smit HE. Assessment of body composition by bioelectrical impedance is strongly agedependent. Eur J Nutr 1990; 44: 261-268

5. Fusch $\mathrm{C}$, Moeller $\mathrm{H}$. Detection of $\mathrm{D}_{2} \mathrm{O}$ concentrations at tracer levels in small samples obtained from pediatric patients. $J$ Clin Chem Clin Biochem 1988; 26: 715-721

6. Fusch C, Spirig N, Moeller H. Fourier transformed infrared spectroscopy (FT-IR) measures ${ }^{1} \mathrm{H} /{ }^{2} \mathrm{H}$ ratios of native water samples with a precision comparable to that of isotope ratio mass spectrometry (IRMS). Eur J Clin Chem Clin Biochem 1993; 31: 639-644

7. Wong W, Cochran W, Klish W, Smith O, Lee S, Klein P. In vivo isotope-fractioning factors and the measurement of deuterium- and oxygen-18-dilution spaces from plasma, urine, saliva, respiratory water vapor, and carbon dioxide. Am J Clin Nutr 1988; 55: 918-923

8. Lukaski HC, Johnson PE, Bolonchuk WW, Lykken GI. Assessment of fat-free mass using bioelectrical impedance measurements of the human body. Am J Clin Nutr 1985; 41: 810-817

9. Schaefer F, Georgi M, Zieger A, Schārer K. Usefulness of bioelectrical impedance and skinfold measurements in predicting fat free mass derived from total body water potassium in children. Pediatr Res 1994; 35: 617-624

10. Hoffer EC, Meador CK, Simpson DC. Correlation of wholebody impedance with total body water volume. $J$ Appl Physiol 1969; 27: 531-534

11. Cheek DB, Mellits D, Elliott D. Body water, height, and weight during growth in normal children. Am J Dis Child 1966; 112: 312-317
12. Slaughter $M H$, Lohman TG, Boileau RA et al. Skinfold equations for estimation of body fatness in children and youth. Hum Biol 1988; 60: 709-723

13. SAS Institute Ind. SAS/STAT User's Guide, Release 6.03 Edition. SAS Institute, Cary, NC, 1988

14. Bohm D, Odaischi M, Beyerlein C, Overbeck W. Total body water: changes during dialysis estimated by bioimpedance analysis. Infusionstherapie 1990; 17: 75-78

15. Davies PSW, Preece MA, Hicks CJ, Halhday D. The prediction of total body water using bioelectrical impedance in children and adolescents. Ann Hum Biol 1987; 15: 237-240

16. Gregory JW, Greene SA, Scrimgeour CM, Rennie MJ. Body water measurement in growth disorders: a comparison of bioelectrical impedance and skinfold thickness techniques with isotope dilution. Arch Dis Child 1991; 66: 220-222

17. Danford LC, Schoeller DA, Kushner RF. Comparison of two bioelectrical impedance analysis models for total body water measurement in children. Ann Hum Biol 1992; 19: 603-607

18. Hoffer E, Meador C. Simpson D. Correlation of whole-body impedance with total body water volume. J Appl Physiol 1969; 27: $531-534$

19. Houtkooper LB, Lohman TG, Going SB, Hall MC. Validity of bioelectrical impedance for body composition assessment in children. J Appl Phystol 1989; 66: 814-821

20. Evans JH, Smye SW, Brooklebank JT. Mathematical modeling of hemodialysis in children. Pediatr Nephrol 1992; 6: 349-353

21. Deurenberg P, van der Kooy, Leenen R, Schouten FJM. Body impedance is largely dependent on the intra- and extracellular water distribution. Eur J Clin Nutr 1989; 43: 845-853

22. Patterson R. Body fluid determinations using multiple impedance measurements. Eng Med Biol 1989; 8: 19-28

23. Tedner B, Lins LE. Fluid volume monitoring with electrica impedance technique during hemodialysis. Artif Organs 1984; 8: $66-71$

24. Katzarski K, Anderstam B, Nilsson M, Bergström J. Multifrequency bioimpedance (MFB) in monitoring of fluid changes during haemodialysis (HD) (Abstract). Nephrol Dial Transplant 1994; 9: 990

25. Widdowson EM. Changes in body proportions and composition during growth. In: Davies Ja, Dobbing J, eds. Scientific Foundattons of Pediatrics. Heinemann Medical Books Ltd, London, 1974; 153-163

26. Cameron N. The Measurement of Human Growth. Croom Helm, London 1984 